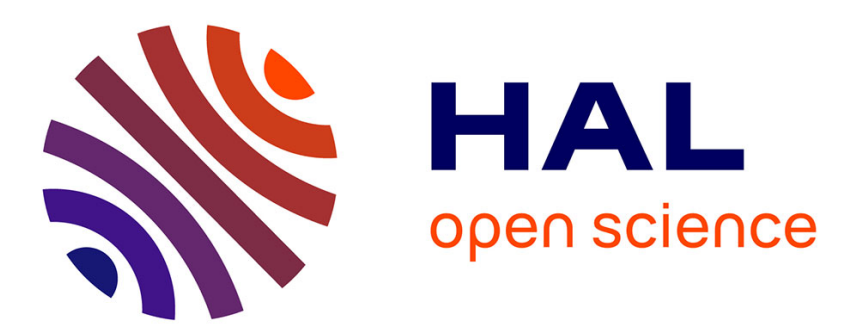

\title{
Iridium(III) Catalyzed Z-Selective Allylic Arylation of $\alpha$-Fluoro But-1-enoic Acid Amides via $\beta$-F-Elimination in Water
}

Clément Casalta, Christophe Gourlaouen, Samir Bouzbouz

\section{To cite this version:}

Clément Casalta, Christophe Gourlaouen, Samir Bouzbouz. Iridium(III) Catalyzed Z-Selective Allylic Arylation of $\alpha$-Fluoro But-1-enoic Acid Amides via $\beta$-F-Elimination in Water. Organic Letters, 2021, 10.1021/acs.orglett.1c02054 . hal-03447277

\section{HAL Id: hal-03447277 \\ https://hal.science/hal-03447277}

Submitted on 24 Nov 2021

HAL is a multi-disciplinary open access archive for the deposit and dissemination of scientific research documents, whether they are published or not. The documents may come from teaching and research institutions in France or abroad, or from public or private research centers.
L'archive ouverte pluridisciplinaire HAL, est destinée au dépôt et à la diffusion de documents scientifiques de niveau recherche, publiés ou non, émanant des établissements d'enseignement et de recherche français ou étrangers, des laboratoires publics ou privés. 


\title{
Iridium (III) catalyzed $Z$-selective Allylic Arylation of $\alpha$-fluoro but-1-enoic acid amides via $\beta$-F-elimination in Water
}

\author{
Clément Casalta ${ }^{\mathrm{a}}$, Christophe Gourlaouen ${ }^{\mathrm{b}}$, Samir Bouzbouz ${ }^{\mathrm{a}}$
}

a) CNRS, University of Rouen, INSA, COBRA UMR 6014 76800, Mont Saint Aignan, France

b) Laboratoire de Chimie Quantique, Institut de Chimie de Strasbourg, UMR 7177 CNRS-Université de Strasbourg, 67070

Strasbourg, France

KEYWORDS (Word Style “BG_Keywords"). If you are submitting your paper to a journal that requires keywords, provide significant keywords to aid the reader in literature retrieval.

\begin{tabular}{|c|c|c|c|}
\hline & 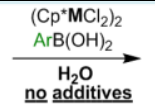 & $\mathrm{HN}-{ }_{0}^{-}-\mathrm{Ar}$ & $\begin{array}{l}\text { - } 43 \text { examples of mono arylation } \\
2 \text { examples of bis arylation } \\
\text { - High Regioselectivity } \\
\text { Gram scale }\end{array}$ \\
\hline $\begin{array}{l}M=I r \\
M=R h\end{array}$ & $\begin{array}{l}5.4: 1-29: 1 \\
1: 2-4: 1\end{array}$ & $38-79 \%$ of $Z$-product & $\begin{array}{l}\text { - Wide temperature range } 40 \text { to } 80^{\circ} \mathrm{C} \\
\text { - Wide substrate scope }\end{array}$ \\
\hline
\end{tabular}

ABSTRACT: Allylic arylation of $\alpha$-fluoro but-1-enoic acid amides with arylboronic acids was carried out in water by comparing the catalytic activity of iridium(III) and rhodium (III). Ir(III) has shown a strong superiority over Rh(III) to give allyl-aryl coupling products with excellent stereoselectivity in favor of the $Z$ isomer. The origin of high stereoselectivity is perhaps because of the a coordination of iridium Ir-N or Ir-O.

The allylic arylation is an versatile reaction for the creation of $\mathrm{a} \mathrm{Csp}_{(\mathrm{Ar})}{ }^{-} \mathrm{Csp}^{3}$ bond. ${ }^{1-5}$ Different metals were used in this reaction. Among these metals, iridium, which has demonstrated its reactivity in many transformations ${ }^{6}$ was rarely during allylic arylation. ${ }^{7}$ In addition, during allylic arylations, the products obtained possess olefins with an predominant $E$ stereochemistry. Although the synthesis of $E$-alkenes is well established, the synthesis of $Z$-alkenes is less represented, particularly from an allylic substitution process. The direct synthesis of $\gamma$-aryl-(Z)$\alpha, \beta$-unsaturated amides of type $\mathbf{I}$ remains a major challenge. The synthesis of these compounds was accomplished either through a cross metathesis reaction of acrylamides ${ }^{8}$ (disconnection 1) or via assisted $\mathrm{C}-\mathrm{H}$ alkylation ${ }^{9}$ (disconnection 2) (Scheme 1a). Recently, our group reported the first $\left(\mathrm{Cp} * \mathrm{Rh}(\mathrm{III}) \mathrm{Cl}_{2}\right)_{2}$ catalyzed allylic arylation in water. This reaction occurred regioselectively at the $\gamma$ position of the $\alpha$-fluoro but-1-enoic acid amides of type $\mathbf{A}$ to produce $\gamma$-substituted- $\alpha, \beta$ unsaturated amides with high $Z$ selectivity (Scheme $1 b) .{ }^{10}$ During this study we observed that reactivity and stereoselectivity were controlled by the coordination effect of the amide and the steric effect of the substituent $\mathbf{R}$ of the double bond. During this study, the role of $\mathbf{R}$ substituent of the double bond is essential. This role of the $\mathbf{R}$ substituent is so decisive that its absence resulted in deterioration of the $Z / E$ ratio (Scheme $1 c$ ).

Herein, we report the synthesis of ( $Z$ )- $\alpha, \beta$-unsaturated amides I from $\alpha$-fluoro but-1-enoic acid amides of type $\mathbf{B}$ via $\mathrm{Z}$-selective allylic arylation catalyzed by $\left(\mathrm{Cp}^{*} \mathrm{Ir}(\mathrm{III}) \mathrm{Cl}_{2}\right)_{2}$ (disconnection 3) (Scheme 1d). To compensate for the absence of the steric effect, we decided to focus our work on the coordination effect of the metal used in the catalyst by comparing the catalytic activity of $\left(\mathrm{Cp}^{*} \mathrm{IrCl}_{2}\right)_{2}$ and $\left(\mathrm{Cp}^{*} \mathrm{RhCl}_{2}\right)_{2}$. Iridium(III) has been described as a harder and stronger Lewis acid than rhodium(III) due to the relativistic contraction of iridium. This difference in the Lewis acid character of iridium compared to rhodium influences the catalytic activity of the two complexes AM1 and AM2, which have a different reactivity on $\alpha$-fluoro but-1-enoic

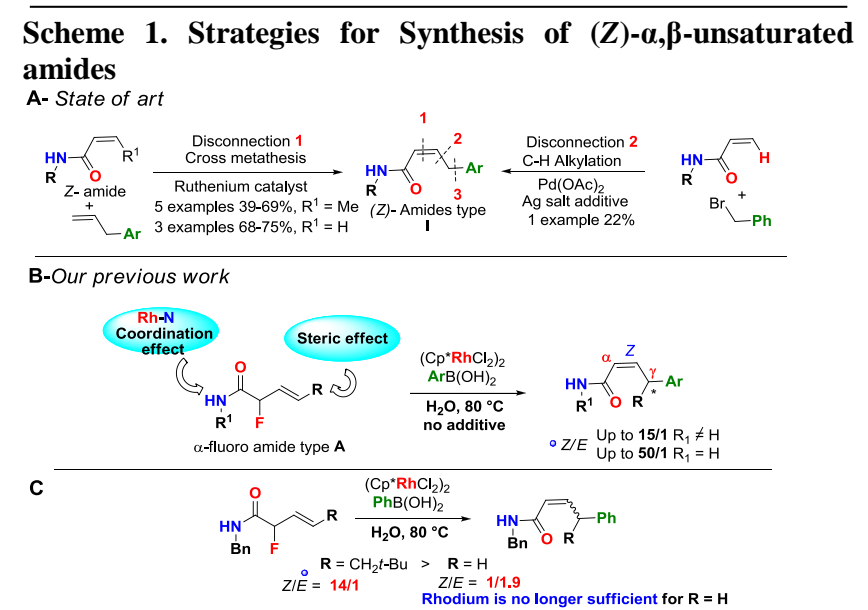

D- Present Work : Z-selective Allylic Arylation by Iridium (III) catalysis in water via $\beta$-F elimination

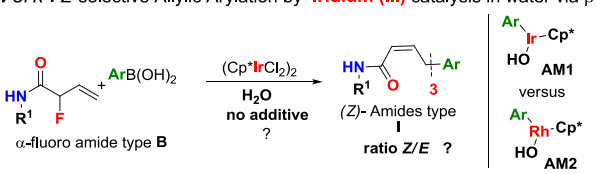

acid amides of type $\mathbf{B}$. The metals $(\mathrm{M}=\mathrm{Rh}$, Ir) have different modes of $\mathbf{M}-\mathrm{N}$ and $\mathbf{M}-\mathrm{O}$ coordination with amides. ${ }^{11}$

To verify the postulate, we probed the reaction conditions for allylic arylation catalyzed by rhodium and iridium on the secondary amide 1a with phenylboronic acid in water and without additives (Table1). As anticipated, the desired transformation has proven to be highly efficient and the nature of the metal appeared to have a considerable effect on the stereoselectivity of the product. Indeed, the reaction with iridium favored $Z$-isomer Z-2aa $(Z / E=6.6: 1)$, while with rhodium provided a mixture of isomers $(Z / E=1: 1.9)$ (entries 2,3$)$. In the reaction with rhodium, we observed the bis-arylation product of resulting from the 1,4 addition of phenyl boronic acid onto 2aa. On the 
other hand, when 1 eq of boronic acid is used, no bis-arylation product was observed with the Rh(III) catalyst (see SI for details S7).This secondary product was not formed with iridium.

\section{Table 1. First comparison studies between $\mathrm{Ir}$ and $\mathrm{Rh}^{\mathrm{a}}$}

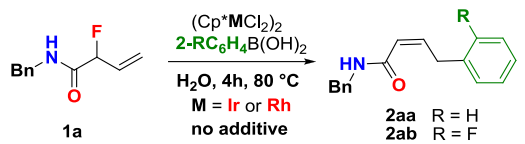

$\begin{array}{ccccc}\text { entry } & \text { Catalyst }(\mathrm{mol} \%) & \mathrm{R} & \begin{array}{c}\text { yield } \\ (\%)^{b, c}\end{array} & \mathrm{Z} / \mathrm{E} \\ 1 & - & \mathrm{H} & \mathrm{N} . \mathrm{R} & - \\ 2 & \left(\mathrm{Cp} * \mathrm{RhCl}_{2}\right)_{2} & \mathrm{H} & 59^{b} & \mathbf{1 : 1 . 9} \\ 3 & \left(\mathrm{Cp} * \mathrm{IrCl}_{2}\right)_{2} & \mathrm{H} & 60^{c} & \mathbf{6 . 6 : 1} \\ 4 & \left(\mathrm{Cp} * \mathrm{RhCl}_{2}\right)_{2} & \mathrm{~F} & 96^{b} & \mathbf{2 : 1} \\ 5 & \left(\mathrm{Cp} * \mathrm{IrCl}_{2}\right)_{2} & \mathrm{~F} & 70^{c} & \mathbf{1 9 : 1} \\ 6 & \left(\mathrm{Cp} * \mathrm{IrCl}_{2}\right)_{2}{ }^{d} & \mathrm{~F} & 72^{c} & 19: 1 \\ 7^{e} & \left(\mathrm{Cp} * \mathrm{IrCl}_{2}\right)_{2} & \mathrm{~F} & 72^{c} & 19: 1\end{array}$

${ }^{a}$ Reaction conditions: 1a $(0.5 \mathrm{mmol}), \mathrm{ArB}(\mathrm{OH})_{2}(1 \mathrm{mmol})$, catalyst $4 \mathrm{~mol}$ $\%, \mathrm{H}_{2} \mathrm{O}(1 \mathrm{~mL}) .{ }^{\mathrm{b}}$ Yields of $\mathrm{Z}+\mathrm{E}$ isomers determined by ${ }^{1} \mathrm{H}$ NMR analysis of the crude reaction mixture using $\mathrm{CH}_{2} \mathrm{Br}_{2}$ as internal standard. ${ }^{\mathrm{c}}$ Yield of isolated $Z$-product. ${ }^{\mathrm{d}}$ catalyst $10 \mathrm{~mol} \mathrm{\%}$. ${ }^{\mathrm{e}}$ Premixed catalyst and water $(\mathrm{C}=$ $0.1 \mathrm{M})$ at $80{ }^{\circ} \mathrm{C}$ for 40 min followed by addition $1 \mathrm{a}$ and $\mathrm{ArB}(\mathrm{OH})_{2}$

To check whether the difference in stereoselectivity is sensitive to the substituents of the arylboronic acid, the reaction was performed with arylboronic acid containing a fluoro substitution at the ortho position. Employing $\mathrm{Rh}(\mathrm{III})$ catalyst produced the product 2ab with 2:1 Z/E ratio, whereas the reaction with $\operatorname{Ir}(\mathrm{III})$ gave 2ab with an excellent $Z / E$ ratio of 19:1 (entries 4,5 ). Inrease in the catalyst loading (entry 6) as well as the premixing of the catalyst in water ${ }^{12}$ before adding the catalyst and the substrates did not alter the $Z / E$ ratio (entry 7$)$. It is important to note that the $\beta$-fluorine elimination process is very fast and stereoselective compared to $\beta$-acetoxy elimination as shown by NMR (see SI for details S8-9). However, the reaction did not work at all in $\mathrm{CH}_{3} \mathrm{CN}$, toluene, THF, DMSO, HFIP and $\mathrm{iPrOH}$ (see SI for details S10). We also established a kinetic profile of the Ir(III) catalyzed reaction (4 mol\%) of 1a with 2-fluorophenylboronic acid over a period of $28 \mathrm{~h}$ (see SI for details S11-12). This profile clearly shows that at a temperature of $80{ }^{\circ} \mathrm{C}$ the ratio $(Z / E=19: 1)$ remains constant up to $4 \mathrm{~h}$ and that beyond this time we observe an erosion of the $Z / E$ ratio up to $14: 1$. Performing the reaction with 1,2 and $3 \mathrm{~mol} \%$ of $\operatorname{Ir}(\mathrm{III})$ catalyst in the reaction of $\mathbf{1 a}$ and 2-fluorophenylboronic acid, formation of the $Z$ isomer is predominant (see SI for S13). The Z/E ratio increases by lowering the temperature but requires a long time of 24 hours. These interesting results show that this iridium catalyzed arylation reaction can be carried out over a wide temperature range (see SI for details of the boronic acid $(2 \mathrm{~F}, 2 \mathrm{Cl}$ and 2Br) S14-19). For the rest of the study, we chose the temperature $80{ }^{\circ} \mathrm{C}$ with a short time of 4 hours. Taking into account the notable difference in stereoselectivity observed in the first two examples between the catalysts $\left(\mathrm{Cp}^{*} \mathrm{IrCl}_{2}\right)_{2}$ and $\left(\mathrm{Cp}^{*} \mathrm{RhCl}_{2}\right)_{2}$, we explored the reaction of allylic arylation with different arylboronic acids. These results can be classified into two groups (Scheme 2). In the first group, all substituted or disubstituted aryl boronic acids in the meta and para position $\left(\mathrm{F}, \mathrm{Cl}, \mathrm{CH}_{3}\right.$, $\mathrm{CF}_{3}, \mathrm{OH}, \mathrm{OCF}_{3}, \mathrm{NHCOCH}_{3}, \mathrm{CO}_{2} \mathrm{CH}_{3}$ ) except 3-bromophenylboronic acid were used as reactants. The $Z$-products (2aa, 3-16) were obtained with a yield varying between $57-72 \%$.
Scheme 2. Investigation of the arylboronic substrates scope $^{\mathrm{a}, \mathrm{b}, \mathrm{c}}$
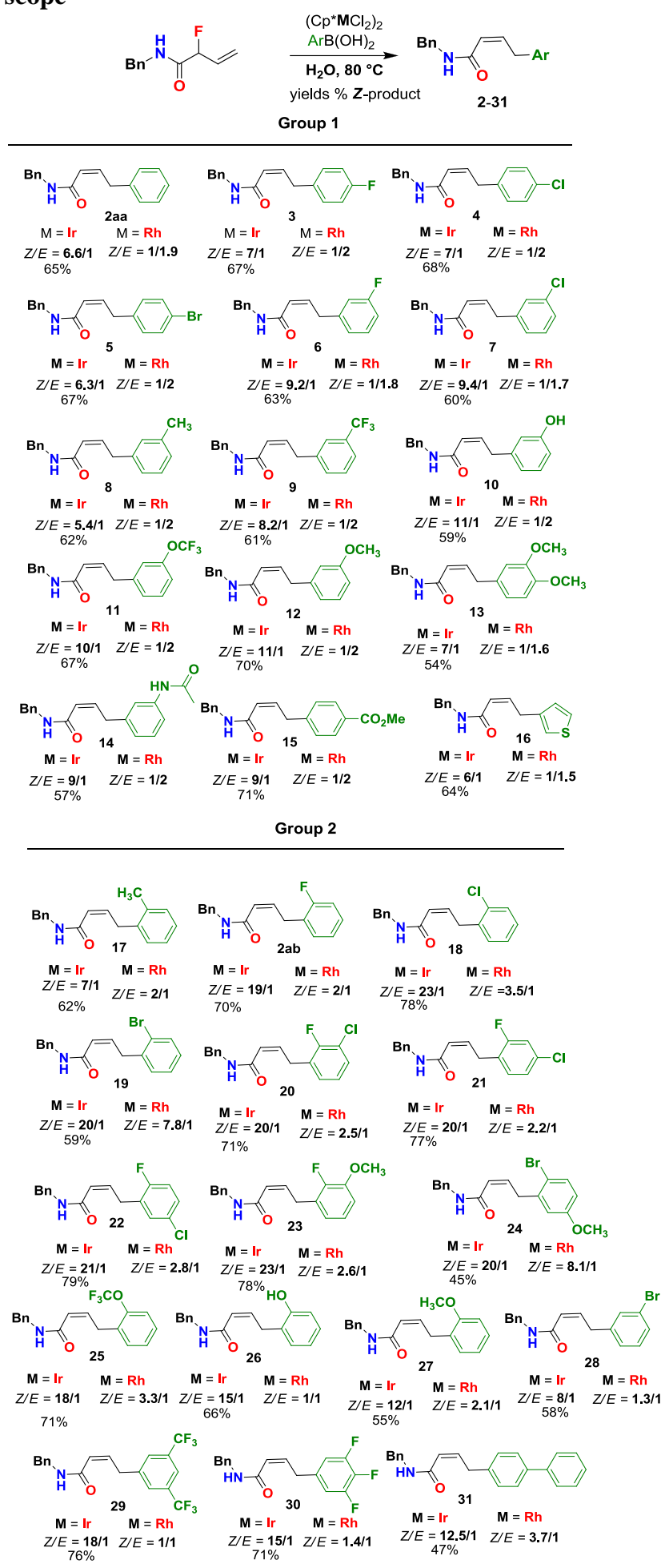

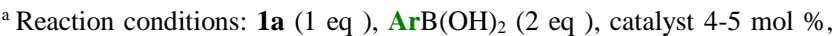
$\mathrm{H}_{2} \mathrm{O}(\mathrm{C}=0.52 \mathrm{M})$ see $\mathrm{SI}$. ${ }^{\mathrm{b}}$ Isolated yield of Z- product. ${ }^{\mathrm{c}}$ ratio $\mathrm{Z} / E$ determined by $1 \mathrm{H}$ NMR analysis of the crude reaction.

The second group contains aryl boronic acids substituted at the ortho and the arylation products $(\mathbf{2 a b}, \mathbf{1 7}-\mathbf{2 7})$ were obtained with the iridium catalyst with a $Z / E$ ratio varying between $7: 1$ and 20:1. In the second group, the case of di and trisubstituted compounds $\mathbf{2 9}$ and $\mathbf{3 0}$ is particularly noted, which are obtained 
with high $Z / E$ ratio in comparison with the monosubstituted compounds 9 and $\mathbf{6}$ of the first group. The superiority of iridium $(Z / E=9: 1$ to $29: 1)$ over rhodium $(Z / E=1: 1.6$ to $2.2: 1)$ has been confirmed with other secondary and primary fluorinated amides $\mathbf{1 b}-\mathbf{1 g}$ (Scheme 3 ). The $Z$-products (32-42) were obtained with a yield varying between $38-74 \%$. It is worth notingshould be noted that when 4-pyridylboronic acid is used in the presence of iridium (III) no reaction was observed, the starting product remains unchanged. Presumably, pyridylboronic acid breaks the Ir-amide bond and deactivates the catalyst.

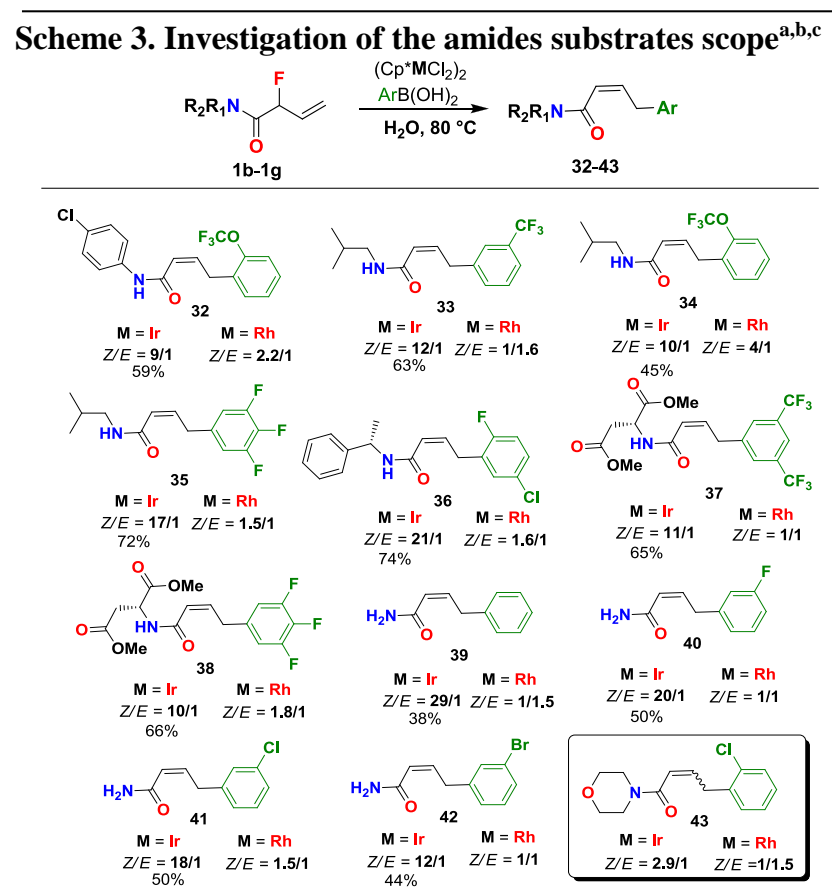

${ }^{\mathrm{a}}$ Reaction conditions: $\mathbf{1 b}-\mathbf{1 g}(1 \mathrm{eq}), \mathrm{ArB}(\mathrm{OH})_{2}(2 \mathrm{eq})$, catalyst 4-5 mol \%, $\mathrm{H}_{2} \mathrm{O}(\mathrm{C}=0.35-0.97 \mathrm{M})$ see supporting information. ${ }^{\mathrm{b}}$ Isolated yield of $\mathrm{Z}$ product. ${ }^{c}$ ratio $Z / E$ determined by $1 \mathrm{H}$ NMR analysis of the crude reaction.

It is important to note the case of tertiary amide $\mathbf{4 3}$, the use of a hindered aryl boronic and despite the absence of $\mathrm{NH}$, iridium gave the product with $Z$ olefin as a major isomer $(Z / E=2.9: 1)$ while rhodium gave the product with $E$ olefin as a major isomer $(Z / E=1: 1.7)$. This demonstrates that an Ir-O type coordination cannot be ruled out.

\section{Scheme 4. Isomerization Studies with catalysts and with or} without arylboronic

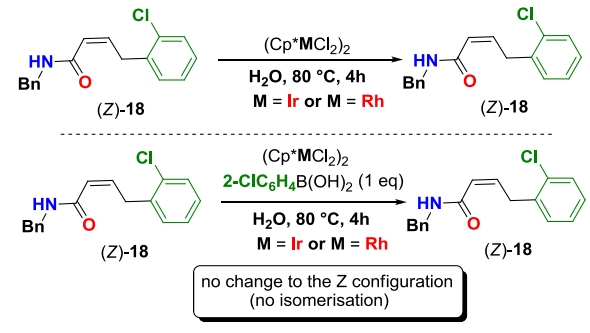

Interestingly, the $Z$ configuration of isolated product $(Z)$ was found to be unaltered upon exposure to the iridium or rhodium catalysis procedure with or without arylboronic acid, thereby excluding a post arylation isomerization process (Scheme 4) (see SI for details S20-21).
Scheme 5. Plausible mechanism for Z-Allylic Arylation in water.

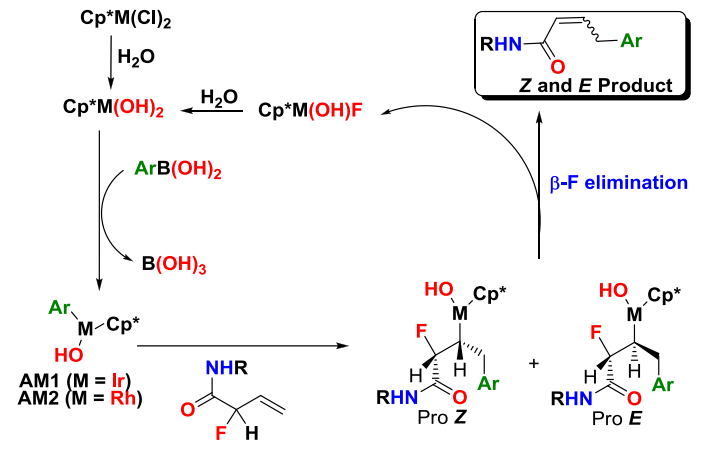

We assume that after transmetallation, the insertion of the aryl metal is done after $\eta^{2}$-coordination of the $\mathrm{C}-\mathrm{C}$ double bond on the cation. This step is assisted by the coordination of the $\mathrm{N}$ or $\mathrm{O}$ atom or without coordination, which are only different rotamers of the same structure. The migratory insertion thus leading to the intermediate pro $Z$ and pro $E$. $\beta$-F-elimination ${ }^{13,14}$ from the proZ and Pro $E$ intermediates leads to the product $Z$ and $E$ olefins respectively. At this stage, the preference for the formation of the Z-olefin from the reaction with AM1 (M= Ir) is not clear. The theoretical and experimental investigations to elucidate the difference in formation of $Z$ and $E$ olefin products with the iridium and rhodium catalysts used is under investigation. ${ }^{15}$

The fact that we obtain the $Z$ olefin, we believe that a $\pi$-metalallyl intermediate is a less possibility, although recently such a $\mathrm{Z}$ olefin was obtained via $\pi$-metal-allyl intermediate starting from a $Z$ olefin. ${ }^{16,17} \mathbf{A M 1}$ and $\mathbf{A M 2}$ lead to different isomer ratio. In an attempt to explain this difference, we performed reactions with both catalysts simultaneously. The results obtained from seven significant examples indicate a drop in the $Z / E$ ratio, but remains in favor of the $Z$ isomer, which shows that the iridium is better in the presence of rhodium. This result indicates that the catalytic activity of the two arylmetals AM1(Ir) and AM2 (Rh) is very different (see SI for details S22-23).

\section{Scheme 6. The bis allylic arylation and large-scale reaction}

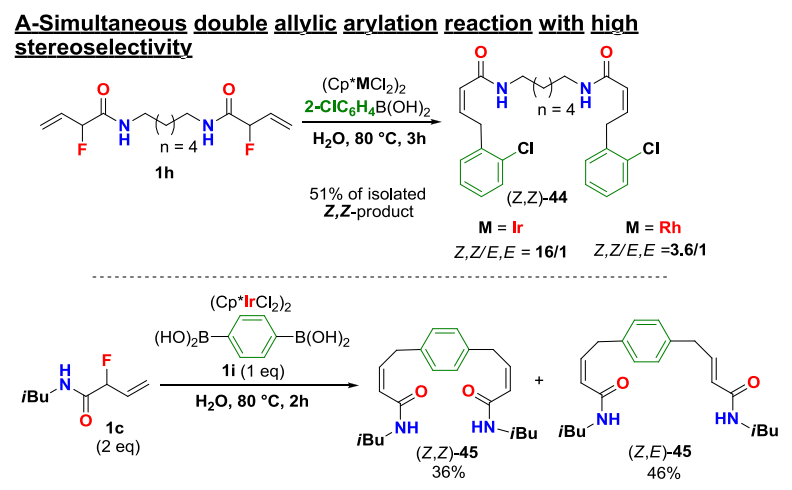

B-Large-Scale of allvlic Arvlation reaction

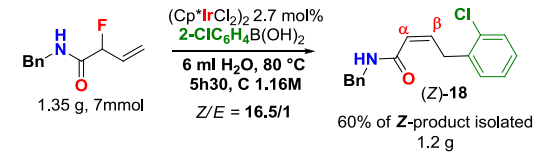


This reaction is also effective in the biarylation of the bis amide $1 \mathrm{~h}$ and with a substrate a substrate having two boronic acid sites 1i (Scheme 6A). In both cases, we were able to obtain and isolate new molecular architectures (Z,Z)-44, (Z,Z)-45 and $(Z, Z)-\mathbf{4 5}$ with satisfactory yields. These two examples show the robustness of this arylation reaction in water, which is also demonstrated by the gram-scale reaction of 1a, and 2-chlorophenylboronic acid. The desired ( $Z$ ) $\mathbf{- 1 8}$ acrylamide was obtained in $65 \%$ yield (Scheme 6B). The synthetic transformations via functionnalisation of $\alpha$ and $\beta$ positions of compound 18 were carried out. (see SI for details S45-49 and S213233).

In summary, we established Ir-catalyzed selective reaction between functionalized allylic fluoride and arylboronic acids to obtain unsaturated Z-amides via the creation of a Csp2-Csp3 bond. In this study, we have demonstrated the superiority of the Ir(III) catalyst over Rh(III) in the formation of the product.

\section{ASSOCIATED CONTENT}

\section{Supporting Information}

The Supporting Information is available free of charge at https://pubs.acs.org.

General information, experimental procedures, characterization data, and NMR spectra (PDF).

\section{AUTHOR INFORMATION}

\section{Corresponding Author}

*E-mail: samir.bouzbouz@ univ-rouen.fr

\section{ORCID}

Samir Bouzbouz: 0000-0002-5544-7892

\section{Notes}

The authors declare no competing financial interest.

\section{ACKNOWLEDGMENT}

C.C. thanks the Ministry of Higher Education and Research for a $\mathrm{PhD}$ grant. This work was partially supported by the Centre National de la Recherche Scientifique (CNRS), University of Rouen, INSA Rouen, Labex SynOrg (ANR-11-LABX-0029)

\section{REFERENCES}

(1) For reviews on the transition metal-catalyzed cross-coupling reactions, see: (a) Metal-Catalyzed Cross-Coupling Reactions, ed. A. de Meijere and F. Diederich, Wiley-VCH, Weinheim, 2nd edn, 2008; (b) Handbook of Organopalladium Chemistry for Organic Synthesis, ed. E.-I. Negishi and A. de Meijere, Wiley-VCH, Weinheim, 2002. For reviews on SuzukiMiyaura coupling, see: (c) A. Suzuki, Angew. Chem., Int. Ed., 2011, 50, 6723; (d) G. A. Molander and B. Canturk, Angew. Chem., Int. Ed., 2009, 48, 9240; (e) N. Miyaura and A. Suzuki, Chem. Rev. 1995, 95, 2457. For reviews on the Tsuji-Trost allylic substitutions, see: (f) G. Helmchen, U. Kazmaier and S. Forster, in Catalytic Asymmetric Synthesis, ed. I. Ojima, Wiley, Hoboken, 3rd edn, 2010, pp. 497-641; (g) B. M. Trost and M. L. Crawley, Chem. Rev. 2003, 103, 2921; (h) J. Tsuji, Acc. Chem. Res., 1969, 2,144 .

(2) For references concerning allylic arylation in the recent article Ohtaka, A. ; Kawase, M. ; Usami, A. ; Fukui, S. ; Yamashita, M. ; Yamaguchi, K. ; Sakon, A. ; Shiraki, T. ; Ishida, T. ; Nagata, S. ; Kimura, Y. ; Hamasaka, G. ; Uozumi, Y.; Shinagawa, T. ; Shimomura, O.; Nomura, R.. ACS Omega 2019, 4, 15764.
(3) (a) Zhang, X.-M.; Yang, J.; Zhuang, Q.-B.; Tu, Y.-Q.; Chen, Z.; Shao, H.; Wang, S.-H.; Zhang, F.-M. Allylic arylation of 1,3-dienes via hydroboration/migrative Suzuki-Miyaura cross-coupling reactions. ACS Catal. 2018, 8, 6094. (b) Ghorpade, S. A.; Sawant, D. N.; Renn, D.; Zernickel, A.; Du, W.; Sekar, N.; Eppinger, J. Aqueous protocol for allylic arylation of cinnamyl acetates with sodium tetraphenylborate using a Bedford-type palladacycle catalyst. New J. Chem. 2018, 42, 6210. (c) Nallasivam, J. L.; Fernandes, R. A. Pd-catalyzed site-selective mono-allylic substitution and bisarylation by directed allylic C-H activation: Synthesis of anti- $\gamma$-(aryl, styrel)- $\beta$ hydroxy acids and highly substituted tetrahydrofurans. J. Am. Chem. Soc. 2016, 138, 13238. (d) Hamasaka, G.; Sakurai, F.; Uozumi, Y. A palladium NNC-pincer complex: an efficient catalyst for allylic arylation at parts per billion levels. Chem. Commun. 2015, 51, 3886. (e) Hamasaka, G.; Sakurai, F.; Uozumi, Y. A vesicular self-assembled amphiphilic palladium NNC-pincer complex-catalyzed allylic arylation of allyl acetates with sodium tetraarylborates in water. Tetrahedron 2015, 71, 6437. (f) Dong, Z.; Ye, Z. Heterogeneous palladium catalyst constructed with cross-linked hyperbranched poly(phenylacetylene) as polymer support: A reusable highly active ppm-level catalyst for multiple cross-coupling reactions. Appl. Catal., A 2015, 489, 61. (g) Watanabe, K.; Mino, T.; Abe, T.; Kogure, T.; Sakamoto, M. Hydrazone-palladium-catalyzed allylic arylation of cinnamyloxyphenylboronic acid pinacol esters. J. Org. Chem. 2014, 79, 6695. (h) Dong, Z.; Ye, Z. Reusable, Highly Active Heterogeneous Palladium Catalyst by Convenient Self-Encapsulation Cross-Linking Polymerization for Multiple Carbon-Carbon Cross Coupling Reactions at ppm to ppb Palladium Loadings. Adv. Synth. Catal. 2014, 356, 3401. (i) Shintani, R.; Tsuji, T.; Park, S.; Hayashi, T. Palladium-catalyzed intramolecular decarboxylative allylic arylation of $\alpha$-aryl- $\gamma$-methylidene- $\delta$-valerolactones. Chem. Commun. 2010, 46, 1697. (j) Yamada, Y. M. A.; Watanabe, T.; Torii, K.; Uozumi, Y. Catalytic membrane-installed microchannel reactors for onesecond allylic arylation. Chem. Commun. 2009, 45, 5594.

(4) Allylic arylation of allyl alcohol: (a) Wang, G.; Gan, Y.; Liu, Y. NickelCatalyzed Direct Coupling of Allylic Alcohols with Organoboron Reagents. Chin. J. Chem. 2018, 36, 916. (b) Zhang, Y.; Yin, S.-C.; Lu, J.-M. $\mathrm{N}$-Heterocyclic carbene-palladium(II)-1-methylimidazole complex catalyzed allyl-aryl coupling of allylic alcohols with arylboronic acids in neat water. Tetrahedron 2015, 71, 544. (c) Wu, H.-B.; Ma, X.-T.; Tian, S.-K. Palladium-catalyzed stereospecific cross-coupling of enantioenriched allylic alcohols with boronic acids. Chem. Commun. 2014, 50, 219. (d) Tsukamoto, H.; Uchiyama, T.; Suzuki, T.; Kondo, Y. Palladium(0)-catalyzed direct cross-coupling reaction of allylic alcohols with aryl- and alkenylboronic acids. Org. Biomol. Chem. 2008, 6, 3005. (e) Manabe, K.; Nakada, K.; Aoyama, N.; Kobayashi, S. Cross coupling reactions of allylic alcohols in water. Adv. Synth. Catal. 2005, 347, 1499. (f) Tsukamoto, H.; Sato, M.; Kondo, Y. Palladium(0)-catalyzed direct cross-coupling reaction of allyl alcohols with aryl- and vinyl-boronic acids Chem. Сотmun. 2004, 1200.

(5) Catalysts other than Pd: (a) Gonzalez, J.; Schäfer, P.; Fletcher, S. P. Highly enantioselective Hiyama cross-coupling via Rh-catalyzed allylic arylation of racemic allyl chlorides. Organometallics 2019, 38, 20, 3991. (b) Schafer, P.; Palacin, T.; Sidera, M.; Fletcher, S. P. Asymmetric SuzukiMiyaura coupling of heterocycles via rhodium catalyzed allylic arylation of racemates. Nat. Commun. 2017, 8, 15762. (c) Guduguntla, S.; Hornillos, V.; Tessier, R.; Fañanas-Mastral, M.; Feringa, B. L. Chiral diarylmethanes via copper-catalyzed asymmetric allylic arylation with organolithium compounds. Org. Lett. 2016, 18, 252. (d) Sidera, M.; Fletcher, S. P. Rhodiumcatalysed asymmetric allylic arylation of racemic halides with arylboronic acids. Nat. Chem. 2015, 7, 935. (e) Kaloğlu, M.; Şahin, N.; Semeril, D.; Brenner, E.; Matt, D.; O' 'zdemir, I.; Kaya, C.; Toupet, L. Copper-catalysed allylic substitution using 2,8,14,20-tetrapentylresorcinarenyl-substituted imidazolium salts. Eur. J. Org. Chem. 2015, 2015, 7310. (f) Srinivas, H. D.; Zhou, Q.; Watson, M. P. Enantiospecific, nickel-catalyzed cross-couplings of allylic pivalates and arylboroxines. Org. Lett. 2014, 16, 3596. (g) Selim, K. B.; Nakanishi, H.; Matsumoto, Y.; Yamamoto, Y.; Yamada, K.i.; Tomioka, K. Chiral N-Heterocyclic Carbene-Copper(I)-Catalyzed Asymmetric Allylic Arylation of Aliphatic Allylic Bromides: Steric and Electronic Effects on $\gamma$-Selectivity. J. Org. Chem. 2011, 76, 1398. $\gamma$-Selective process in allylic arylation reaction (h) Ohmiya, H.; Makida, Y.; Li, D.; Tanabe, M.; Sawamura, M. Palladium-Catalyzed $\gamma$-Selective and Stereospecific Allyl-Aryl Coupling between acyclic allylic esters and arylboronic Acids. J. Am. Chem. Soc. 2010, 132, 879. (i) Ohmiya, H.; Makida, Y.; Tanaka, T.; Sawamura, M. Palladium-catalyzed $\gamma$-selective and stereospecific allyl-aryl coupling between allylic acetates and arylboronic Acids. $J$. Am. Chem. Soc. 2008, 130, 17276. (j) Nishikata, T.; Lipshutz, B. H.Allylic 
ethers as educts for Suzuki-Miyaura couplings in water at room temperature. J. Am. Chem. Soc. 2009, 131, 12103 (k) Selim, K. B.; Matsumoto, Y.; Yamada, K.-i.; Tomioka, K. Efficient chiral Nheterocyclic carbene/copper(I)-catalyzed asymmetric allylic arylation with aryl Grignard reagents. Angew. Chem., Int. Ed. 2009, 48, 8733. (1) Miura, T.; Takahashi, Y.; Murakami, M. Rhodium-catalysed substitutive arylation of cis-allylic diols with arylboroxines. Chem. Commun. 2007, 595.

(6) (a) Rössler, S. L.; Petrone, D. A.; Carreira, E, M, Iridium-Catalyzed Asymmetric Synthesis of Functionally Rich Molecules Enabled by (Phosphoramidite,Olefin) Ligands. Acc. Chem. Res. 2019, 52, 2657. (b) Cheng, Q.; Tu, H. F.; Zheng, C.; Qu, J. P.; Helmchen, G.; You, S. Li. IridiumCatalyzed Asymmetric Allylic Substitution Reactions. Chem. Rev. 2019, $119,1855$.

(7) Allylic arylation with Iridium catalyst (a) Hua Tian, H.; Zhang, P.; Peng, F.; Yang, H.; Hua, F. Chiral Cyclic Ligand-Enabled Iridium-Catalyzed Asymmetric Arylation of Unactivated Racemic Allylic Alcohols with Anilines Org. Lett. 2017, 19, 3775. (b) Alexakis, A.; El Hajjaji, S.; Polet, D. Rathgeb, X. Iridium-Catalyzed Asymmetric Allylic Substitution with Aryl Zinc Reagents Org. Lett. 2007, 9, 3393. (c) Polet, D.; Rathgeb, X.; Falciola, C. A.; Langlois, J.-B.; El Hajjaji, S.; Alexakis, A. Enantioselective iridiumcatalyzed allylic arylation. Chem. Eur. J. 2009, 15, 1205.

(8) (a) Liu, Z.; Xu, C.; del Pozo, J.; Torker, T.; Hoveyda, A. H. Ru basedcatechothiolate complexes bearing an unsaturated NHC ligand: Effective cross-metathesis catalysts for synthesis of (Z)- $\alpha, \beta$-unsaturated esters, carboxylic acids, and primary, secondary, and weinreb amides. J. Am. Chem. Soc. 2019, 141, 7137. (b) Efficient Z-Selective Olefin-Acrylamide CrossMetathesis Enabled by Sterically Demanding Cyclometalated Ruthenium Catalysts. Xu,Y.; Wong, J. J.; Samkian, A. E.; Ko J. H.; Chen, S.; Houk, K. N.; Grubbs, R. H. J. Am. Chem. Soc. 2020, 142, 20987.

(9) Cheng, X.; Chen, Z.; Gao, Y.; Xue, F.; Jiang, C. Aminoquinoline-assisted vinylic $\mathrm{C}-\mathrm{H}$ arylation of unsubstituted acrylamide for the selective synthesis of Z olefins. Org. Biomol. Chem., 2016, 14, 3298.

(10) Casalta, C.; Bouzbouz, S. Rhodium(III) Catalyzed Regioselective and Stereospecific Allylic Arylation in Water by $\beta$-Fluorine Elimination of the Allylic Fluoride: Toward the Synthesis of Z-Alkenyl-Unsaturated Amides. Org. Lett. 2020, 22, 2359.

(11) (a) Park,Y.; Heo, J.; Baik, M. H.; Chang, S. Why is the Ir(III)-Mediated Amido Transfer Much Faster Than the Rh(III)-Mediated Reaction? A Combined Experimental and Computational Study. J. Am. Chem. Soc. 2016, 138, 14020. (b) Li, X.; Wu, H.; Lang, Y.; Huang, G. Mechanism, selectivity, and reactivity of iridium and rhodium-catalyzed intermolecular ketone $\alpha$-alkylation with unactivated olefins via an enamide directing strategy. Catal. Sci. Technol., 2018, 8, 2417. (c) Manoharan, R.; Jeganmohan, M. Recent Advancements in Allylic C(sp3)-H Functionalization of Olefins Catalyzed by $\mathrm{Rh}(\mathrm{III})$ or Ir(III) Complexes Eur. J. Org. Chem. 2020, 2020, 7304.

(12) $\left(\mathrm{Cp}^{*} \mathrm{IrCl}_{2}\right)_{2}$ is hydrolyzed in of water $(\mathrm{C}=0.1 \mathrm{M})$ at $80{ }^{\circ} \mathrm{C}$ to obtain a yellow solution of the cation $\left[\mathrm{Cp} * \operatorname{Ir}\left(\mathrm{H}_{2} \mathrm{O}\right)_{3}\right]^{2+}$

Dadd, L.; Elias, H.; Frey, U.; Hornig, A.; Koelle, U.; Merbach, A. E.; Paulus, H.; Schneider, J. S. $\pi$-Arene Aqua Complexes of Cobalt, Rhodium, Iridium, and Ruthenium: Preparation, Structure, and Kinetics of Water Exchange and Water Substitution. Inorg. Chem. 1995, 34, 306.

(13) For references interaction Fluor-Metal associated of syn or anti $\beta$-Felimination (a) Review Fu-jita, T.; Fuchibe, K.; Ichikawa, J. Transitionmetal-mediated and cata-lyzed $\mathrm{C}-\mathrm{F}$ bond activation by fluorine elimination. Angew. Chem., Int. Ed. 2019, 58, 390. Rh-F interaction (b) Li, T.; Zhou, C.; Yan, X.; Wang, Jun Solvent-Dependent Asymmetric Synthesis of Alkynyl and Monofluoroalkenyl Isoindolinones by Cp*RhIII-Catalyzed C-H Activation Angew. Chem., Int. Ed. 2018, 57, 4048. (c) Gao, H.; Sun, M.; Zhang, H.; Bian, M.; Wu, M.; Zhu, G.; Zhou, Z.; Yi, W. Stereoselective $\beta$-F Elimination Enabled Redox-Neutral [4 + 1] Annulation via Rh(III)Catalyzed $\mathrm{C}-\mathrm{H}$ Activation: Access to Z-Monofluoroalkenyl Dihydrobenzo[d]isoxazole Framework Org. Lett. 2019, 21, 5229. Co-F interaction (c) Zell, D.; Müller, V.; Dhawa, U.; Bursch, M.; Presa, R. R.; Grimme, S.; Ackermann, L. Mild Cobalt(III)-Catalyzed Allylative C-F/C-H Functionalizations at Room Temperature Chem. Eur. J. 2017, 23, 12145. Mn-F in- teraction (d) $\mathrm{C}-\mathrm{F} / \mathrm{C}-\mathrm{H}$ Functionalization by Manganese(I) Catalysis: Expedient (Per)Fluoro-Allylations and Alkenylations Zell, D.; Dhawa, U.; Müller, V.; Bursch, M.; Grimme, S.; Ackermann, L. ACS Catal. 2017, 7, 4209. Ir-F interaction (e) Romanov-Michailidis, F.; Ravetz, B. D.; Paley, D. W.; Rovis, T. Ir(III)-Catalyzed Carbocarbation of Alkynes through Undirected Double C-H Bond Activation of Anisoles J. Am. Chem. Soc. 2018, 140,5370 .

(14) Recent articles on syn $\beta$-F-elimination $\mathbf{C u}-\mathrm{F}$ interaction (a) O'Connor, T. J.; Mai, B. K.; Nafi J.; Liu, P.; Toste, F. D. Generation of Axially Chiral Fluoroallenes through a Copper Catalyzed Enantioselective $\beta$-Fluoride Elimination J. Am. Chem. Soc. 2021, 143, 13759.

(15) Preliminary calculations showing the formation pathways of pro $Z$ and Pro $E$ for the two metals Iridium and rhodium are described in Figure TH1 SI for details S234.

(16) Jiang, R.; Ding, L.; Zheng, C.; You, S. L Iridium-catalyzed Z-retentive asymmetric allylic substitution reactions Science 2021, 371, 380 .

(17) Calculation also showed that going through a $\pi$-allyl complex is not favoured with our catalyst. The associated barrier $\left(36.7 \mathrm{kcal} \mathrm{mol}^{-1}\right)$ being inconsistent with experimental results (Figure TH2 in SI for details S235). 